\title{
Magnetoferritin: A Novel Magnetic Protein Cage Nanocarrier
}

\author{
Sumedha Bobade*, K. Vijayarani, K.G. Tirumurugaan, A. Thangavelu, \\ S. Vairamuthu and G. Kalaiselvi \\ Department of Animal Biotechnology, Madras Veterinary College, TANUVAS, \\ Chennai (Tamilnadu), India \\ *Corresponding author
}

\begin{abstract}
A B S T R A C T

\begin{tabular}{|c|c|}
\hline $\begin{array}{l}\text { Ke y words } \\
\text { Appoferritn, } \\
\text { Ferritin, Fenobody } \\
\text { Magnetoferritin, } \\
\text { Nanotechnology }\end{array}$ & $\begin{array}{l}\text { Nanotechnology is the rapidly expanding field and nanoparticles are omnipresent. } \\
\text { Biological nanoparticles are assembled from molecules or atoms synthesized in a } \\
\text { biological system. They include magnetosomes, lipoproteins, viruses, exosomes and } \\
\text { ferritins.. A typical instance of a protein cage possessing this native biological function is } \\
\text { ferritin. This engineered ferritin, which has the same architecture as natural } \mathrm{H} \text {-ferritin, is }\end{array}$ \\
\hline Article Info & shell (apoferritin) and accommodates various metal ions. During the last two decades, the \\
\hline $\begin{array}{l}\text { Accepted: } \\
\text { 04 January } 2019 \\
\text { Available Online: } \\
\text { 10 February } 2019\end{array}$ & $\begin{array}{l}\text { their core to design novel hybrid bioinspired nanoparticles Such hybrid nanoparticles } \\
\text { represent an opportunity for advanced nanotechnology applications in the nanodevices, } \\
\text { disease diagnosis and therapy, drug delivery, vaccine development and bioassay. }\end{array}$ \\
\hline
\end{tabular}
\end{abstract}

\section{Introduction}

Nanoparticles are the spearheads of the rapidly expanding field of nanotechnology. Among all classes of biological nanoparticles ferritins, an ubiquitous iron storage and transport proteins found in most living organisms, eubacteria, archea, plants and animals except yeast. Ferritin was discovered in 1937 by Laufberger, as a novel protein structure for storing and transporting iron molecules isolated it from horse spleen. The FRT superfamily can be divided into three subfamilies: the classical FRTs; the bacterioferritins (BFRs); and the DNA- binding proteins from starved cells (DPSs). Ferritins have been classified as maxiferritins and miniferritins. The maxiferritins, $12 \mathrm{~nm}$ in diameter with $8 \mathrm{~nm}$ diameter cavities, formed from 24 subunits (MW $\approx 480 \mathrm{kDa}$ ); and miniferritins, also called DNA protection during starvation proteins, $8 \mathrm{~nm}$ in diameter with $5 \mathrm{~nm}$ diameter cavities, formed from 12 subunits ( $\mathrm{MW} \approx 240 \mathrm{kDa}$ ).

The classic ferritin (Ftn), found in eukaryotes and some bacteria, is a four-helix bundle protein of around 200 amino acids. Some bacteria and archaea possess bacterioferritin (Bfr), The mini-ferritin, DNA-binding Protein 
from Starved cells (DPS), was initially discovered in Escherichia coli cells during the stationary phase and is found in many bacteria and some archaea and its primary role is to protect the bacterial chromosome from oxidative damage (He and Wright, 2015).Ferritin is a large protein of $450 \mathrm{kDa}$ composed of 24 subunits that self-assemble into a spherical complex cage-like structure. One molecule of ferritin stores up to 4,500 iron atoms.

Fig.1 Structure of Ferritin
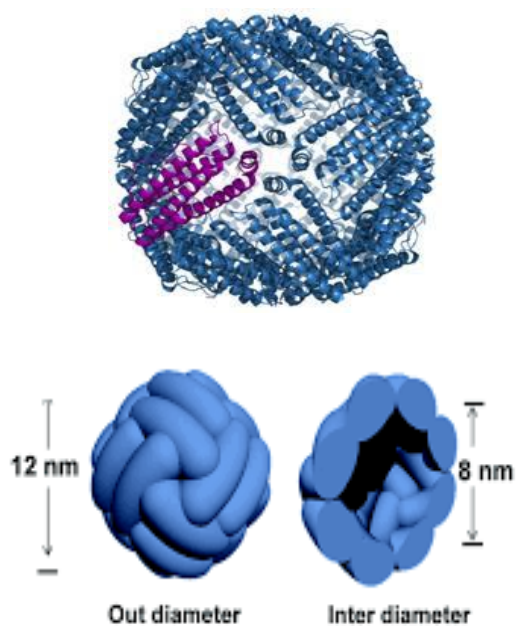

The emergence of nanotechnology, ferritin nanoparticle has been biomimetically synthesized using H-chain ferritin as a template, which self-assembles to form a 24subunit cage-like nanostructure, with an internal iron oxide core (Fig. 1). This engineered ferritin, has same architecture as natural $\mathrm{H}$-ferritin, is termed magnetoferritin. The structural and biochemical properties of ferritin protein are used for tailoring it to a wide range of applications, from the synthesis of nanoparticles to the design of vaccines in biomedicine (He and Wright, 2015).

\section{Appoferritin}

The iron storage protein ferritin consists of a spherical polypeptide shell (apoferritin) surrounding a 6-nanometer inorganic core of the hydrated iron oxide ferrihydrite $\left(5 \mathrm{Fe}_{2} 03\right.$ $9 \mathrm{H}_{2} \mathrm{O}$ ). The incorporation of magnetite into the apoferritin has been conducted to manufacture magnetoferritin. The magnetic property of magenetoferritin, which contains magnetite $\left(\mathrm{Fe}_{3} \mathrm{O}_{4}\right)$ instead of the hydrated iron oxide, has been implied to have potential in biomedical and industrial applications, such as an information storage device and for biomedical imaging. The structure of apoferritin is remarkably stable and robust, and it is able to withstand biologically extreme temperatures (up to $70^{\circ} \mathrm{C}$ ) and a wide $\mathrm{pH}$ range $(\mathrm{pH} 2.0-10.0)$ for an appreciable period of time without significant disruption of their quaternary structure.

\section{Application}

Ferritin is itself a catalytic bionanoparticle and nanocarrier, a safer choice, when engineered or appropriately distributed in a biological system.

\section{Drug delivery}

Mosca et al., (2017) studied the ability of ferritin to bind and deliver metals and metalbased drugs to human neuroblastoma $\mathrm{SH}-$ SY5Y cells. They used heavy chain $(\mathrm{H})$ ferritin-based metal-containing nanocarriers used for the delivery of toxic molecules to brain cells, Iron-containing nanocarriers have a proliferative effect and ferritins can be used for the delivery of toxic molecules to brain tumors. Liang et al., 2014, developed a natural $\mathrm{H}$-ferritin (HFn) nanocarrier that delivered the therapeutic drug doxorubicin (Dox) to tumor cells and significantly inhibited tumor growth with excellent biocompatibility and safety profiles in murine cancer models.

\section{Bioassay}

Fan et al., 2018 developed a novel platform and named fenobody by substituting the fifth 
helix of ferritin with the nanobody, in which a nanobody developed against H5N1 The fenobody system presents a suitable platform for various large-scale biotechnological processes and should greatly facilitate the application of nanobody technology in these areas.

Genetically functionalized ferritin nanoparticles with a high-affinity protein binder can be utilized as a signal generator in a variety of immunoassays and imaging. The repebody-functionalized ferritin nanoparticles can be effectively used for sensitive and specific immunoassays and imaging in many areas (Kim et al., 2017).

Uchida et al., 2006 synthesized an iron oxide (magnetite) nanoparticle within the interior cavity of a genetically engineered human $\mathrm{H}$ chain ferritin (HFn) capable to serve as a multifunctional nanoscale container for simultaneous iron oxide loading and cellspecific targeting.

Charlton et al., 2016, Ferritin is a naturally occurring iron storage protein, proposed as a clinically relevant nanoparticle with applications as a diagnostic and therapeutic agent. Cationic ferritin is a targeted, injectable contrast agent to measure kidney microstructure with MRI.

\section{Vaccine development}

Fusion of eight influenza hemagglutinin (HA) trimers or engineered HA stem antigens to Helicobacter pylori ferritin greatly improved $\mathrm{NAb}$ responses against influenza in animals (Kanekiyo et al., 2013). Human ferritin heavy-chain nanoparticle (hFTH) is genetically engineered to present tumor receptor-binding peptides (antibody and/or RGD-derived cyclic peptides, named 4CRGD) on its surface. The specific interactions between receptors on tumor cells and receptor-binding peptides on engineered $\mathrm{hFTH}$ is critical in active tumor cell targeting (Kwon et al., 2016)

Wang et al., 2017 confirmed that the ferritin nanoparticle is a robust platform to present antigenic peptides and ideal system for rational design of immunogens. The feasibility was investigated using the Helicobacter pylori ferritin (Hpf) nanoparticle to present rationally designed gonorrhea vaccines

Ferritin, an iron-containing natural protein nanoparticle, was applied as a biomaterial to improve the self-renewal and differentiation of NSCs and neural progenitor cells (NPCs). This can be applied in neural tissue engineering and cell therapy for neurodegenerative diseases (Lee et al., 2018)..

\section{Cancer therapy}

Hwang et al., 2013, genetically modify apoferritin and generate a universal interface system with high targeting efficiency, in detection of a pancreatic cancer biomarker and used to demonstrate its potential in the facile exchange of nanoprobe components.

In Mouse model study, Human ferritin nanoparticle (HFn) conjugated Arg-Gly-Asp (RGD) enhanced near-infrared fluorescence imaging (Kitagawa et al., 2012) and MRI imaging (Kitagawa et al., 2016) of AAAs in the and II-infused Apo E-/- mouse model.

Iron deficiency is a worldwide nutritional disorder. Iron enriched yeasts and cereals are alternative strategies to diminish iron deficiency. The yeast Saccharomyces cerevisiae lacks ferritin and uses vacuoles as iron storage organelles. The soybean ferritin expression influenced yeast iron metabolism, confirming that yeasts that express soybean seed ferritin could be explored as a novel 
strategy to increase dietary iron absorption (Rosa et al., 2016).

\section{Nano actuation}

Nano actuation is actuation of a specific action using a nanoscale object with or without the input of an external force acting on it. The ferritin nanoparticles dissipate heat when exposed to AC magnetic field which triggered calcium ion influx facilitated by TRPV1 activation. Calcium ion influx initiated transgene expression of insulin. Insulin in turn lowered blood glucose level. This nano actuation application has significant therapeutic benefits (Stanley and Sarah, 2015).

\section{Purification of water}

The quality of natural protein ferritin that can store metal (hydr)oxide nanoparticles of tunable size in its cavity and bind oxyanions can be used in water purification by applying nanotechnology (Hiemstra and Zhao 2016).

In conclusion, the Magnetoferritin can be genetically engineered and chemically addressed to alter their functionalities for future therapeutic applications. This newly emerging biological approach will open up a new path to the fabrication of functional nanostructures based on Magnetoferritin NPs and protein nanocages as nanocarrier. The use of ferritin derivatives has potential to transform the diagnosis and treatment of tumours in situ.

\section{References}

Charlton J., V.M. Pearla, A.R. Denottib, J.B. Leec, S. Swaminathand, Y.M. Scindiad, N.P..Charltone, E.J. Baldelomarf, S.C. Beemang, and K.M. Bennett, 2016. Biocompatibility of ferritin-based nanoparticles as targeted
MRI contrast agents. Nanomedicine. 12(6): 1735-1745.

Fan K., B.Jiang, Z. Guan, J. He, D.Yang, N. Xie, G. Nie, C. Xie, and X. Yan, 2018. Fenobody: A Ferritin-Displayed Nanobody with High Apparent Affinity and Half-Life Extension. Anal. Chem. 90 (9):5671-5677.

He D. and J. M. Wright, 2015 Ferritin family proteins and their use in bionanotechnology. N. Biotechnol. 32(6): 651-657.

Hiemstra T. and W. Zhao 2016. Reactivity of ferrihydrite and ferritin in relation to surface structure, size, and nanoparticle formation studied for phosphate and arsenate. Environ. Sci.: Nano. 3:1265-1279.

Hwang M., J. Lee, K.E. Lee, and K. H. Lee, 2013. Think Modular: A Simple Apoferritin-Based Platform for the Multifaceted Detection of Pancreatic Cancer. ACS Nano. 7 (9): 8167-8174.

Kanekiyo M, C.J. Wei, H.M.Yassine, P.M. McTamney, J.C. Boyington, J.R.R. Whittle, S.S. Rao, W.P. Kong, L. Wang, and G.J. Nabel, 2013. Selfassembling influenza nanoparticle vaccines elicit broadly neutralizing H1N1 antibodies. Nature. 499:102-6.

Kim J., W. Heu, S. Jeong and H. Kim, 2017. Genetically functionalized ferritin nanoparticles with a high-affinity protein binder for immunoassay and imaging. Analytica Chimica Acta. 988:81-88.

Kitagawa T, H Kosuge, M. Uchida, Y Iida, R.L. Dalman and T. Douglas, 2016. RGD targeting of human ferritin iron oxide nanoparticles enhances in vivo MRI of vascular inflammation and angiogenesis in experimental carotid disease and abdominal aortic aneurysm. Journal of magnetic resonance imaging. J Magn Reson Imaging. doi:10.1002/jmri.25459 
Kitagawa T, H. Kosuge, M.Uchida, M.M. Dua, Y Iida, R.L. Dalman, 2012. RGD- conjugated human ferritin nanoparticles for imaging vascular inflammation and angiogenesis in experimental carotid and aortic disease. Mol Imaging Biol., 14(3):315-24.

Kwon K., H.K. Ko, J. Lee, E. J. Lee, K. Kim and J. Lee, 2016.Enhanced In Vivo Tumor Detection by Active Tumor Cell Targeting Using Multiple Tumor Receptor-Binding Peptides Presented on Genetically Engineered Human Ferritin Nanoparticles. Small. 12(31): 4241-53.

Lee J., K. Yang, A.Cho and S.Cho, 2018 Ferritin nanoparticles for improved self renewal and differentiation of human neural stem cells. Biomaterials Research 22:5

Liang M, K. Fan, M. Zhou, D. Duan, J. Zheng, D. Yang, J. Feng and X. Yan, 2014. H-ferritin- nanocaged doxorubicin nanoparticles specifically target and kill tumors with a singledose injection. Proc Natl Acad Sci. 111:14900-149005.

Mosca L., E. Falvo, P.Ceci, E. Poser, I. Genovese, G. Guarguaglini and G. Colotti, 2017. Use of Ferritin-Based
Metal-Encapsulated Nanocarriers as Anticancer Agents. Appl. Sci. 7(101): $1-16$

Rosa D., C.A. Martínez-Garay, J. Fita-Torró, A.M. Romero, M.T. Martínez-Pastor and S. Puig. 2016. Soybean ferritin expression in Saccharomyces cerevisiae modulates iron accumulation and resistance to elevated iron concentrations. Appl Environ Microbiol 82: 3052-3060.

Stanley S. and Sarah A., 2015. Remote regulation of glucose homeostasis in mice using genetically encoded nanoparticles. Nature Medicine. 21(1): 92-98.

Uchida M., M.L. Flenniken, M. Allen, D. A. Willits, B. E. Crowley, S. Brumfield, A.F. Willis, L. Jackiw, M. Jutila, M. J. Young, and T. Douglas, 2006 Targeting of Cancer Cells with Ferrimagnetic Ferritin Cage Nanoparticles. J. Am. Chem. Soc.128 (51): 16626-16633

Wang Z., H. Gao, Y. Zhang, G. Liu, G.Niu, and $X$. Chen, 2017 Functional ferritin nanoparticles for biomedical applications. Front Chem Sci Eng. 11(4): 633-646.

\section{How to cite this article:}

Sumedha Bobade, K. Vijayarani, K.G. Tirumurugaan, A. Thangavelu, S. Vairamuthu and Kalaiselvi, G. 2019. Magnetoferritin: A Novel Magnetic Protein Cage Nanocarrier. Int.J.Curr.Microbiol.App.Sci. 8(02): 182-186. doi: https://doi.org/10.20546/ijcmas.2019.802.022 